\title{
What Does Brain Research Say about Teaching and Learning Mathematics?
}

\author{
Allan Leslie White \\ University of Western Sydney, Australia. \\ $<$ al.white@uws.edu.au>
}

\begin{abstract}
Brain research has shaken our ideas of the structure of the brain and how the brain works. Gone are the ancient ideas of comparing the brain to a machine. Neuroplasticity describes the remarkable ways in which the brain adapts and transforms itself as a result of a change in stimuli. Cognitive exercises have been designed and trialled that improve memory, problem solving abilities, and language skills in aged subjects and in children, as well as reversing the aging process by twenty to thirty years in some adults. Since the decline of behaviourism as a major theoretical influence upon mathematics education, there have been a number of learning theories emphasising thinking and the influences of the social and cultural contexts. Although, brain research is in its infancy, the question arises as to what does brain research add to mathematics teaching and learning in addressing student needs and developing their potential?
\end{abstract}

Keywords: Teaching and learning, neuroplasticity, behaviourism

\section{Introduction}

A long retired and respected Australian mathematics expert and teacher of mine when asked the purpose of mathematics replied.

What is the purpose of Mathematics? To help one realise that a brain is a wonderful part of our body and the more we understand how to use it to refine and analyse our perceptions and develop our capabilities the more likely we are to lead a fuller and longer life.

His statement focuses on mathematics as a construction of the human mind which can be used to develop thinking and to transform lives. Little did he know at the time that an explosion of brain research was to come and change long held notions and accepted practices involving the brain and learning. These notions involved:

\footnotetext{
Descartes's idea of the brain as a complex machine culminated in our current idea of the brain as a computer and in localizationism. Like a machine, the brain came to be seen as made of parts, each one in a preassigned location, each performing a single function, so that if one of the parts was damaged, nothing could be done to replace it; after all, machines don't grow new parts (Doidge, 2008, p. 13)
}

As a result of brain research, Descartes's idea has been abandoned. No longer is the brain seen as a fixed organ. It appears that the brain can reorganise itself. Neuroplasticity was the term given to the remarkable ways in which the brain adapts and transforms itself as a result of a change in stimuli. Brain researchers have shown that: 
Children are not always stuck with mental abilities they are born with; that the damaged brain can often reorganise itself so that when one part fails, another can often substitute; ... One of these scientists even showed that thinking, learning, and acting can turn our genes on and off, thus shaping our brain anatomy and our behaviour (Doidge, 2008, p. xv).

Amazingly, cognitive exercises have been designed and trialled that improve memory, problem solving abilities, and language skills in aged subjects and in children, as well as reversing the aging process by twenty to thirty years in some adults. These exercises have also been used with autistic children with amazing effects on their language skills and their autistic behavioural traits.

Arising out of this abundance of brain research is the question: How does this apply to mathematics teaching and learning? The true efficacy of an education system is not determined by performance on an international comparison examination but resides in how well the system nurtures students in terms of their current needs and their potential. The assumption being that if the system addresses thoroughly a student's current needs and develops a student's potential then the results will be future positive individual and societal life outcomes. It is beyond the scope of this paper to examine this assumption in any comprehensive manner and the rest of this paper only briefly attempts to answer the question of what brain research adds to mathematics teaching and learning in addressing student needs and developing their potential.

\title{
Drill and Practice
}

From international studies and their corresponding ranking or league tables, interest has focused upon high and low scoring countries and this interest has generated greater knowledge of the classroom practice in participating countries.

\begin{abstract}
International studies of mathematics achievement have profound influence on mathematics education worldwide in the past 15 years. Results of studies such as TIMSS and PISA have dominated the agenda of discussion in the mathematics education community as well as among policy makers. Much attention however has been paid on the ranking of countries in the league tables generated from such studies, often without due consideration of the nature of these studies, as well as the contextual factors that affect the performance of students from different countries (Leung, 2012, p. 34).
\end{abstract}

An observation arising from this focus is a characteristic of many mathematics classrooms in SEAMEO (South East Asian Ministries of Education Organisation) countries is the considerable time spent upon mathematics drill and practice. It has been stated that drill and practice are the rice dishes of Asian mathematics classrooms. While this is an over generalisation, the reasons for any concentration on drill and practice are complex as education occurs in a social environment influenced by many cultural traditions that include 
the perceived values of individuals and society, the social structures such as the relationship between parents and children, or between teachers and students.

\footnotetext{
Our contention is that cultural divisions are much more meaningful than political or geographic divisions in explaining differences of educational practices in mathematics (Leung, Graf, \& Lopez-Real, 2006, p. 4).
}

While it is beyond the scope of this paper to do a comprehensive study of all these influences, one that will be discussed briefly is the influence of the learning theories arising from Western sources upon Asian mathematics classrooms.

\section{Behaviourism}

In the first edition of this journal the darkness of behaviourism (White, 2011) was discussed in regards to mathematics teaching and learning. It was appropriate to focus upon the negative influences because that paper concentrated only upon the negative lasting effects of this tradition. Now in the light of brain research, are there positive aspects of behaviourism that should be reconsidered and modified? Perhaps the reasons that many mathematics teachers have resisted the introduction of newer theories of learning such as constructivism and socio-cultural theories are due to their feeling that behaviourism held some truth or value. So this section will briefly describe some features of behaviourism, how it is still the subject of quite fierce debate in the mathematics education community, and what brain research contributes to this debate.

Behaviourism is a philosophical tradition whose foundations were constructed with the assistance of many laboratory based researchers such as Skinner's (1953) theory of using cause and effect to manipulate behaviour by conditioning which emphasised reward and punishments and gave rise to programmed learning and later mastery learning approaches.

The behaviourist teaching approach was based on a framework of behavioural objectives and a hierarchy of levels of mastery. Criterion based pre and post tests often consisting of multiple choice questions were given to students and if a desired level of mastery was achieved then the student progressed to the next level. Failure meant another go at the current level where drill and practice filled the majority of time. The pedagogy involved the teachers demonstrating a skill and then students would then seek to copy and master it. The progression through the levels consisted of a series of simple tasks where a task was broken into small achievable steps. It was common to hear, when referring to this strategy, the saying: A long journey can be achieved by taking small steps. However, the 
dangers of using this approach in the mathematics classroom have been highlighted elsewhere (Brousseau, 1984; Clements, 2004; White, 2011).

The common teacher classroom strategy that reduced a student's role to answering a series of relatively simple questions because the teacher emptied the task of much of its cognitive challenge, was dangerous and destructive. Another consequence in the curriculum was that the more cognitively challenging questions were removed and replaced by simpler ones. When teachers adopted this style in an attempt to help students tackle higher-level mathematics tasks, they denied their students the opportunity to formulate and apply strategies of their own (Clements, 2004). To provide an example of this emptying process, examine the following dialogue.

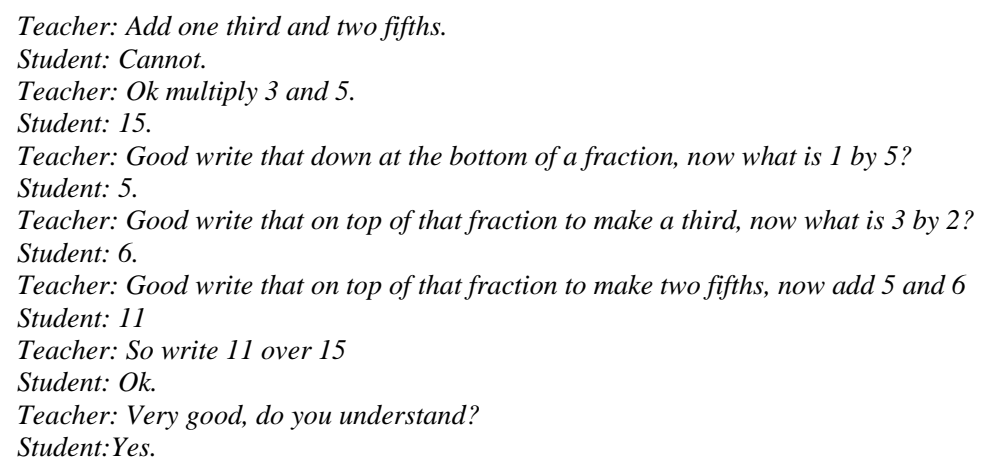

While the teacher's intentions in the dialogue above are kind and helpful, good intentions are not enough. The teacher makes an assumption that if the student answered each step, then the student had learnt what had just been taught, and the student could construct the whole from the parts and thus the student should be able to add two thirds and one half following the same procedure. How deeply do you think this student understands? I predict that the next day, if you asked this student a similar question, the student would struggle to get the correct answer. It would depend upon the student's memory of the procedure. Apart from the use of memory, other aspects of thinking were not used.

Breaking a task down on the surface seems to resonate with our experience, but it all depends on how this breaking is done. If I ask a student a question and they show they do not understand, then, is it not usual to ask a simpler question? If I show a child a procedure and they do not understand, do I not scaffold their thinking by asking further questions and making the steps smaller and simpler? The answer is of course that behaviourism wasn't interested in thinking, but only on behaviour and behavioural outcomes. It is the later learning 
theories that shifted the focus to thinking and the influences of the social and cultural contexts upon the learning of students.

There is a crucial distinction between a strategy that empties a mathematical problem of challenge and a strategy that gradually increases the level of challenge presented to the students by differentiating the curriculum and catering for individual needs. It is this second strategy that current learning theories seek to address. Skemp (1976) would classify the student's understanding in the dialogue above as instrumental. The best we could say is that the student has an understanding of a procedure. A deeper understanding of the concept will require a different teaching strategy and learning experience.

This strategy of cognitive emptying has been shown by a large number of research studies to have poor results and students' were often unable to apply this learning to other novel problems. Brain research helps answer why mathematics teachers are often frustrated when students are able to use a procedure correctly one day but cannot remember how to do the same thing on the next day, as though the brain treats it as new. The reasons are:

\footnotetext{
Students may diligently follow the teacher's instructions to memorize facts or perform a sequence of tasks repeatedly, and may even get the correct answers. But if they have not found meaning by the end of the learning episode, there is little likelihood of long-term storage (Sousa, 2008, p. 56).
}

So in the dialogue presented earlier, unless the student has formed some meaning from the teachers instructions, then the teachers instructions will not be remembered. The fact that some teachers have to do so much reteaching and revision before the end of year examination reflects upon their teaching and the lack of help to students in constructing meaning rather than the usual blame being aimed at the intelligence of the student.

\section{The Maths Wars}

Now the reader might think that surely behaviourism has no influence in our current enlightened times, but the reader would be wrong. It became obvious by the end of the 1970s that the behaviourist teaching approaches were problematic and there was a need for change (Clements, 2003, 2004).

Some of the heaviest criticisms of mathematics teaching and learning is the reliance on drill and practice as a pedagogy. Reform pedagogies have attempted to shift the ideology of drill and practice to one where the learner engages with deep learning so that there is a clear shift from procedural thinking/learning to conceptual thinking/learning (Jorgenson \& Lowrie, 2012, p. 382). 
In the 1980s there was a strong move by mathematics education researchers in Western countries away from behaviourism although it still continues to exert influence. An example can be seen in the current debate between researchers in the USA involving what has become known as the 'Math Wars'. These so called wars were triggered by the publication in 1989 of the Curriculum and Evaluation Standards for School Mathematics by the National Council of Teachers of Mathematics (NCTM, 1989) and developed into a debate between two camps, the traditionalists and the reformist (Becker \& Jacobs, 2000; Schoenfeld, 2004). One particularly extreme traditional group called themselves 'Mathematically Correct' and used aggressive tactics to voice their views. A fuller treatment of the history and context of this debate is available elsewhere (see Schoenfeld, 2004). However the war is not over, as recently, a respected international academic made a public statement alleging bullying and improper conduct by two researchers from the traditionalist camp (Boaler, 2012). The academic had completed a series of different studies thatasserted that students who engaged actively in their mathematics learning and constructed meaning, rather than simply practicing procedures, achieved at higher levels. Those from the traditionalist side opposed these assertions and have conducted a campaign to discredit the researcher.

There are other battles rather than wars being fought elsewhere, for example, the debate over the nature of the curriculum concerned with both the nature of disciplinary knowledge and the nature of learning. One side wants more practical mathematics (functionally relevant), while the other side wants pure theoretical mathematics (mathematical rigour). Thus the first side wants to make the mathematics relevant to the students and to involve real life problem solving often involving the use of mathematical modelling. An example of the influence of this view is Singapore, where modelling and applications are included as process components in the revised 2007 curriculum document (MOE, 2007). This push for relevance has an assumption that being relevant assists students to construct meaning. While the assumption of the pure side is that the mathematics comes first and the applications will follow and they point to the computer and the use of fractals in a multitude of applications as examples.

Another example of the struggle between competing ideas can be found in Indonesia, where there have been efforts to place a stronger emphasis on connecting school mathematics with real world contexts and applications in Indonesian primary schools through the Pendidikan Realistik Matematik Indonesia (PMRI) movement (Sembiring, Hoogland, Dolk, 2010).Yet there is evidence of the other side fighting back, for example in the Netherlands 
there have been calls by various groups for more mathematical rigour and public criticism of the successful and internationally recognised Realistic Mathematics Education approach (van den Heuvel-Panhuizen, 2010).

While most teachers would see the need for both sides to be represented in the classroom, both the practical and the theoretical, brain research points to aspects of teaching and learning that are relevant to both.

\section{Small Challenges Rather Than Simple Steps}

Brain research can contributes to this debate and refers to the classical education of the nineteenth and early twentieth century which developed the brain by learning other languages that strengthened auditory memory, by concentrating on precise handwriting that helped strengthen motor capacities and added speed and fluency to reading, and by placing an emphasis on correct speech and pronunciation.

The irony of this new discovery is that for hundreds of years educators did seem to sense that children's brains had to be built up through exercises of increasing difficulty that strengthened brain functions (Doidge, 2008, p. 41).

Brain research does not support a strategy that empties a mathematical problem of the challenge but it does support a strategy that gradually increases the level of challenge presented to the students to develop the capacities of the brain by differentiating the curriculum and catering for individual needs. For brain research, practice does not make perfect, practice makes permanent and memory fades quickly without meaning.

An example of a successful brain training program that gradually increases the level of challenge is called Fast For Word. This program consists of seven brain exercises and has had remarkable success with language-impaired and learning-impaired children including autistic children. The program is a series of plasticity based techniques and has:

\footnotetext{
... helped hundreds of thousands. Fast For Word is disguised as a children's game. What is amazing about it is how quickly the change occurs. In some cases people who have had a lifetime of cognitive difficulties get better after only thirty to sixth hours of treatment (Doidge, 2008, p. 47).
}

While cognitive challenge, the construction of meaning and thinking are needed as well as drill and practice, brain research has also revealed some interesting things about the quality of student engagement. This issue will be briefly examined in the next section. 


\title{
Engagement, Intensity and Retention
}

Student classroom engagement has received considerable attention as it is argued that decreased engagement can have a negative effect upon a student's future (Sullivan, Mousley, \& Zevenbergen, 2005). One of my colleagues (Attard, 2010, 2011a, b, 2012) conducted a longitudinal case study investigating the problem of lowered engagement with mathematics from the Australian students' perspectives of the factors that influenced their engagement during the middle years of Australian schooling. The study spanned three school years (Years 5-7) and used a multi-dimensional view of engagement that combines the cognitive, operative and affective facets (Fair Go Team NSW Department of Education and Training, 2006; Munns \& Martin, 2005), which leads to students valuing and enjoying school mathematics and seeing connections between school mathematics and their own lives beyond the classroom.

One finding that is worth repeating is in regard to 'fun' in mathematics lessons. The data clearly revealed that aspects of lessons that made them fun were not always based on games but involved their relevance to the students' lives, an element of challenge built into the tasks, and the ability for students to see the mathematics as useful within practical situations. In other words, lessons that promoted affective, operative and cognitive engagement with mathematics.

Apart from this need for challenge, brain researchers have found that the speed at which we think is also plastic. It is possible to train the brain to fire brain neurons more quickly in response to stimuli. The essence of the training lay in paying close attention or intense concentration.

\begin{abstract}
Merzenich discovered that paying close attention is essential to long-term plastic change. In numerous experiments he found that lasting changes occurred only when his monkeys paid close attention. When animals performed tasks automatically, without paying attention... the change did not last. We often praise "the ability to multitask." While you can learn when you divide your attention, divided attention doesn't lead to abiding change in your brain (Doidge, 2008, p. 68).
\end{abstract}

So it seems that the intensity of engagement is the key for stimulating the control centre to produce acetylcholine (helps concentration) and dopamine (pleasure).

\footnotetext{
That's why learning a new language in old age is so good for improving and maintaining the memory generally. Because it requires intense focus, studying a new language turns on the control system for plasticity and keeps it in good shape for laying down sharp memories of all kinds (Doidge, 2008, p. 87).
} 
So the classical education involving the learning of other languages and the demands upon students to pay close attention to their hand writing, speech and pronunciation all played a part in developing the capacities of the brain.

Now during a 40 minute lesson, brain researchers have found that there are optimal times when to demand close attention. We tend to remember best what comes first and second best what comes last and this is known as the primacy-recency effect. In other words there are windows of learning opportunity of new material for teachers where the students are more predisposed to pay close attention. In the figure below, the prime times for learning and retaining new material are shown.

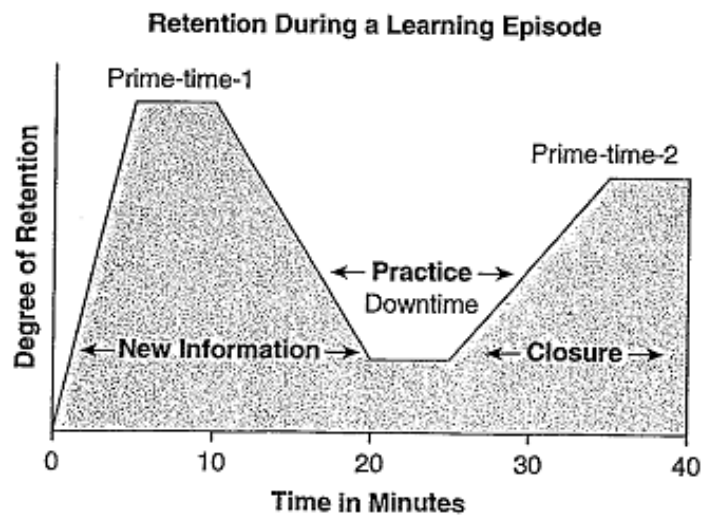

Figure 1. New information can be presented in prime time 1, closure in prime time 2 and practice is appropriate in the downtime. (Sousa, 2008, p. 61)

This has implications for teachers. The usual ways of starting a lesson with roll marking, homework correction and other administrative tasks should be left to the middle of the lesson and the start should involve the introduction of new material in order to maximise the use of this learning window. The end of a lesson should also not conclude with the teacher setting the homework but should involve the teacher assisting the students to connect their new knowledge with their existing knowledge. It makes the lesson closure as nearly as important as the start. It is the final opportunity for the construction of meaning.

An ongoing part of the teaching and learning cycle involves student assessment and all education systems formulate ways of giving feedback to the students in order to communicate desired outcomes and a student's progress towards these outcomes. In the next section, this will be briefly explored. 


\section{Student Feedback}

Technology and the use of digital games have been the focus of considerable current research. Among other issues it has focussed on extending the thinking of students, particularly in literacy and numeracy and upon using levels of challenge and rewards as a means of providing individual feedback to the student. For example, Lowrie (2005) worked with eight-year old students using the Pokemon environment and found that the children worked well beyond the experiences being provided in the standard school curriculum in terms of spatial representation and visualisation. This work highlighted the possibilities of the digital games environment for enhancing mathematical learning and understandings that were beyond the realms of standard pencil-and-paper representations.

Early behaviourism studies used stimulus response experiments and relied on rewards and punishments to change behaviour. This was also adopted into behaviourist teaching strategies and involved using differing feedback strategies to promote behaviour modification. Usually the rewards were forgotten and the punishments involved detentions and corporal punishment. The cane was a recurring nightmare for many a poor student. While behaviourism was unable to satisfactorily explain why this was effective, brain research is able to deepen our understanding of the processes involved.

The early example, the Fast for Word brain training program uses reward as a crucial feature of the program because each time the child receives a reward the brain secretes neurotransmitters such as dopamine and acetylcholine which helps consolidate the brain changes the child has made. Dopamine reinforces the reward while acetylcholine helps concentration and sharpens memory. The reward feeds into the student overcoming the challenge of a particular level. Perhaps one of the many reasons for the popularity of computer games revolves around the fact that the child competes against him or herself and not against a classroom of peers. Certainly individual levels of challenge are better for catering for individual differences. 


\section{Conclusion}

Brain research is still in its infancy regarding applications to education but what has already arisen has added to our understanding of the teaching and learning of mathematics. Mathematics is a rich and powerful context within which students' brains can be challenged, deeply engaged, and rewarded as they struggle to make meaning in their lives. The process of meaning construction involves connected knowledge, and a student's ability with mathematics is plastic and not fixed, and depends upon the experiences and stimulus to the brain. The principle of use it or lose it is a challenge to all mathematics teachers to provide brain stimulation to their students, because:

\footnotetext{
... post-mortem examinations have shown that education increases the number of branches among neurons. An increased number of branches drives the neurons farther apart, leading us to an increase in the volume and thickness of the brain. The idea that the brain is like a muscle that grows with exercise is not just a metaphor (Doidge, 2008, p. 43).
}

As brain research continues to develop and more applications to education are established, I look forward to walking into a mathematics classroom in the future and hearing the students excitedly chant, "Give me more, my brain feels no pain, maths is good for me!" 


\section{References}

Attard, C. (2010). Students' experiences of mathematics during the transition from primary to secondary school. Paper presented at the 33rd annual conference of the Mathematics Education Research Group of Australasia, Fremantle, Perth.

Attard, C. (2011a). Engagement with mathematics: The influence of teachers. Southeast Asian Mathematics Education Journal, 1(1), 31-39.

Attard, C. (2011b). "My favourite subject is maths. For some reason no-one really agrees with me": Student perspectives of mathematics teaching and learning in the upper primary classroom. Mathematics Education Research Journal, 23(3), 363-377.

Attard, C. (2012). The influence of pedagogy on student engagement with mathematics during the middle years of schooling. In A. L. White \& U. H. Cheah (Eds.), Transforming School Mathematics Education in the 21st Century (pp. 140-157). Penang: SEAMEO RECSAM

Becker, J. P., \& Jacobs, B. (2000). The politics of California school mathematics. The antireform of 1997-99.Phi Delta Kappan, 81(7), 529-537.

Bloom, B. S., Englehart, M. D., Furst, E. J., Hill, W. H., \& Krathwohl, D. R. (1956).Taxonomy of Educational Objectives: The Classification of Educational Goals. Handbook I: Cognitive Domain. New York: Longmans, Green \& Co.

Boaler, J. (2012). When Academic Disagreement Becomes Harassment and Persecution. Retrieved 20 October 2012 from http://www.stanford.edu/ joboaler/

Brousseau, G. (1984). The crucial role of the didactical contract in the analysis and construction of situations in teaching and learning mathematics. In H. G. Steiner (Ed.), Theory of mathematics education (pp. 110-119). Bielefeld, Germany: Universität Bielefeld.

Clements, M. A. (2003). Professional practice in mathematics education: Introduction. In A. J. Bishop, M. A. Clements, C. Keitel, J. Kilpatrick, \& F. Leung (Eds.), Second international handbook of mathematics education (pp. 637-641). Dordrecht, The Netherlands: Kluwer Academic Publishers.

Clements, M. A. (2004). Pre-service Teacher Education: Its time for a rethink. Keynote address delivered at the EduCATE 2004 Conference organized by the Faculty of Cognitive Sciences and Human Development (UNIMAS) in collaboration with the Bahagian Pendidikan Guru (Kementerian Pelajaran Malaysia). Kuching Sarawak Malaysia.

Doidge, N. (2008). The brain that changes itself: Stories of personal triumph from the frontiers of brain science (Revised Edition).Melbourne: Scribe Publications Pty Ltd.

Fair Go Team NSW Department of Education and Training. (2006). School is for me: pathways to student engagement. Sydney: NSW Department of Education and Training, Sydney, Australia.

Gagne, R. M. (1968). Contributions of learning to human development. Psychological Review, 75, 177-191.

Jorgenson, R., \& Lowrie, T. (2012).Digital games for learning mathematics: possibilities and limitations. In J. Dindyal, L. P. Cheng \& S. F. Ng (Eds.), Mathematics education: Expanding horizons, (Proceedings of the 35th annual conference of the Mathematics Education Research Group of Australasia, eBook, pp. 378-384). Singapore: MERGA Inc. 
Leung, F. K. S. (2012). What can and should we learn from international studies of mathematics achievement? In J. Dindyal, L. P. Cheng \& S. F. Ng (Eds.), Mathematics education: Expanding horizons, (Proceedings of the 35th annual conference of the Mathematics Education Research Group of Australasia, eBook, pp. 34-60). Singapore: MERGA Inc.

Leung, F. K. S., Graf, K-D., \& Lopez-Real, F. J. (2006). Mathematics education in different cultural traditions: A comparative study of East Asia and the West - A discussion document. In F. K. S. Leung, K-D Graf, F. J. Lopez-Real (Eds.), Mathematics education in different traditions - A comparative study of East Asia and the West (pp. 1-20). New York, NY: Springer.

Lowrie, T. (2005). Problem solving in technology rich contexts: Mathematics sense making in out-of-school environments. Journal of Mathematical Behavior, 24, 275-286.

Ministry of Education (MOE) (2007). Ministry of Education Mathematics Syllabus Primary, Singapore: Curriculum Planning and Developmental Division.

Munns, G., \& Martin, A. J. (2005). It's all about MeE: A motivation and engagement framework. Paper presented at the Australian Association for Academic Research Focus Conference, Cairns. Retrieved 28 September 2012 from http://www.aare.edu.au/05pap/mun05400.pdf

National Council of Teachers of Mathematics (NCTM).(1989). Curriculum and evaluation standards for school mathematics. Reston, VA: Author

Schoenfeld, A. (2004). The Math Wars. Educational Policy, 18(1), 253-286.

Sembiring, R. K., Hoogland, K., \& Dolk, M. (2010). A decade of PMRI in Indonesia. Utrecht: APS International.

Skemp, R. R. (1976). Relational understanding and instrumental understanding. Mathematics Teaching, 77, 20-26.

Skinner, B. F. (1953). Science and human behavior. New York: Free Press.

Sousa, D. A. (2008). How the brain learns mathematics. Thousand Oaks, CA: Corwin Press.

Sullivan, P. (2011). Teaching mathematics : using research-informed strategies. Australian Education Review; no. 59.Camberwell, VIC: ACER press.

Sullivan, P., Mousley, J., \& Zevenbergen, R. (2005). Increasing access to mathematical thinking. The Australian Mathematical Society Gazette, 32(2), 105-109.

van den Heuvel-Panhuizen, M. (2010). Reform under attack: Forty years of working on better mathematics education thrown on the scrapheap? No way! In L. Sparrow, B. Kissane \& C. Hurst (Eds.), Proceedings of MERGA 33 conference: Shaping the future of mathematics education (Vol. 1, pp. 1-25). Fremantle, Western Australia: MERGA.

White, A. L. (2011). School mathematics teachers are super heroes. South East Asia Mathematics Education Journal, 1(1), 3-17. 